\title{
Synthesis and Characterization of TGA-capped CdSe QDs for Electrochemiluminescence (ECL) Biosensor
}

\author{
Jun-Hee Ye, Eueng-Young Jung and Seong-Ho Choi* \\ Department of Chemistry, Hannam University, Daejeon 305-811, Republic of Korea \\ * Corresponding author
}

\begin{abstract}
In order to detection to low level glucose concentration, an ECL biosensor based on TGA-capped CdSe QDs was fabricated by the immobilization of CdSe QDs after modifying the surface of a glassy carbon electrode (GCE) with 4aminothiophenol diazonium salts by the electrochemical method. For the detection of glucose concentration, and glucose oxidase (GOD) was immobilized onto the fabricated CdSe QDs-modified electrode. The fabricated ECL biosensor based on TGA-capped CdSe QDs was characterized using a scanning electron microscope (SEM), UV-vis spectrophotometry, transmission electron microscopy (TEM), fluorescence spectrometer (PL), and cyclic voltammetry (CV). The fabricated ECL biosensor based on TGA-capped CdSe QDs is suitable for the detection of glucose concentrations in real human blood samples.
\end{abstract}

Keywords-thioglycol acid; cadmium selenide; quantum dots; electrogenerated chemiluminescence; biosensor

\section{INTRODUCTION}

ECL biosensors have been generally fabrication through the immobilization of ruthenium complexes $\left(\mathrm{Ru}(\mathrm{bpy})^{32+}\right)$ on glassy carbon electrodes (GCE) modified with conducting composite polymer $[1,2]$. However, these sensors tend to decrease ECL intensity, reproducibility, and stability because the conducting composite polymer composed of MWNT, $\mathrm{SiO}_{2}$ nanospheres, or Au nanoparticles often separate from the GCE surface during electrochemical testing. Besides, this method is limited by the complicated and expensive instrumentation.

With the development of nanotechnology, semiconductor nanocrystals such as quantum dots (QDs) have attracted considerable interest due to significant advantages of sizedependent electronic and optic properties, which have been extensively studied and applied in recognition and detection in biometry [3, 4]. A remarkable increase in ECL intensity has been reported for quantum dot (QD) composites with carbon nanotubes deposited on electrode surfaces, graphene, carbon paste electrodes, and nanoparticles. Among the detection techniques in the biomedical field, ECLs based on a QD system have been known for offering a wide range of advantages such as broad excitation spectra, narrow emission spectra, and low cost [5-7].
In this study, a novel ECL biosensor based on functionalized GCE and CdSe QDs was prepared to improve their high sensitivity, selectivity, serviceability, low-cost, and stability. First of all, the CdSe QDs were synthesized in an aqueous solution using an amino acid, L-cysteine, which is stable and biocompatible. An ECL biosensor based on CdSe QDs was prepared by the modification of GCE with MWNT and CdSe QDs, and then Acetylcholinesterase (AChE) was immobilized on the surface to react with acetylcholine. Furthermore, the fabricated ECL biosensor can be applied to the quantitative and qualitative analysis of Alzheimer's through the determination the $\mathrm{H}_{2} \mathrm{O}_{2}$ as the final product from reaction of acetylcholine which is a main component in Alzheimer's disease.

\section{EXPERIMENTAL}

MWNT (95\%; length $10 \mu \mathrm{m}$ ) were obtained from Hanwha Nanotech (South Korea). Cadmium sulfate hydrate $\left(\mathrm{CdSO}_{4} \cdot(3 / 8) \mathrm{H}_{2} \mathrm{O}\right)$ was obtained from Junsei Chemical (South Korea), and selenium powder (Se powder), sodium nitrite $\left(\mathrm{NaNO}_{2}\right)$, 4-aminothiophenol (4-ATP), Sodium borohydride $\left(\mathrm{NaBH}_{4}\right), \mathrm{D}-(+)$-glucose and glucose oxidase (GOD, 17300 unit/g) were purchased from Sigma-Aldrich (USA). Phosphate buffer solution (PBS) was prepared by mixing stock solutions of $\mathrm{NaH}_{2} \mathrm{PO}_{4}$ and $\mathrm{Na}_{2} \mathrm{HPO}_{4}$, and then adjusting to $\mathrm{pH}=7.0$. All solutions for the experiments were prepared with water purified in a Milli-Q plus water purification system (Millipore, USA). Glassy carbon electrodes were purchased from Bioanalytical System (USA) (model MF-2012).

FIGURE I. shows the preparation procedure of the thioglycol acid (TGA)-capped CdSe QDs using reduction reagents. The Se powder $(0.02 \mathrm{~g}), \mathrm{NaBH}_{4}(0.10 \mathrm{~g})$ in ethanol $(15.0 \mathrm{~mL})$ was added in left side round flask and stirred until dissolving. On the other round flask, the $\mathrm{CdCl}_{2}(0.01 \mathrm{~g})$, TGA $(0.01 \mathrm{~g})$ with $\mathrm{NaOH}$ in $50 \mathrm{~mL}$ water at $90^{\circ} \mathrm{C}$ was dissolved. After then the $0.1 \mathrm{M} \mathrm{H}_{2} \mathrm{SO}_{4}$ was dropped in left side round flask using dropping funnel in order to prepare $\mathrm{H}_{2} \mathrm{Se}$ gas. The preparation mechanism of the TGA-capped CdSe QDs are also shown in FIGURE I. As results, we could obtain the TGAcapped CdSe QDS with various size as control reaction time. 


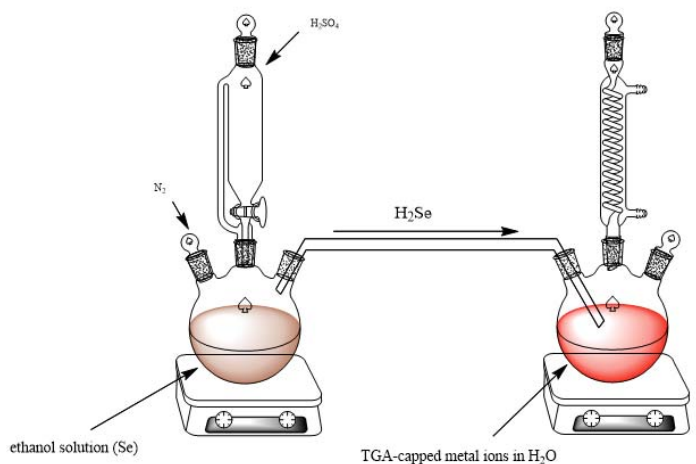

FIGURE I. SCHEMATIC PREPARATION PROCEDURE OF THE THIOGLYCOL ACID (TGA)-CAPPED CdSe QDs USING REDUCTION REAGENTS
Cyclic voltammetry (CV) was performed using a Potentiostat/Galvanostat model 283. (Ametek PAR, USA) and a conventional three-electrode system comprising a composite-coated glassy carbon (diameter $2 \mathrm{~mm}$ ) working electrode, a platinum wire counter electrode, and an Ag/AgCl (saturated $\mathrm{KCl}$ ) reference electrode. Electrochemical signals were recorded using an H7468-01 photomultiplier tube (PMT) system (Hamamatsu Photonics, Japan). The entire ECL cell was enclosed in a light-proof dark box. ECL measurements were carried out in $0.1 \mathrm{M}$ PBS ( $\mathrm{pH}$ 7). The applied working potential ranged from 0 to $-2.0 \mathrm{~V}$ and the cycle scan rate was $100 \mathrm{mV} / \mathrm{s}$. A high voltage power supply of $750 \mathrm{~V}$ was applied to the PMT and all experiments were performed 10 times.

\section{RESUlts AND Discussion}

Quantum dots are widely used not only in the photoelectrochemical field but also in biosensors, biological

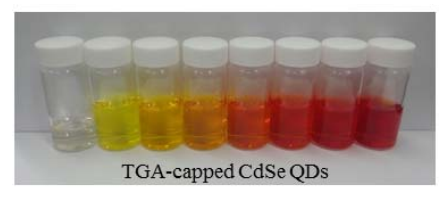

$\mathrm{NaBH}_{4}+\mathrm{Se}+3 \mathrm{C}_{2} \mathrm{H}_{5} \mathrm{OH} \longrightarrow \mathrm{NaHSe}+\mathrm{B}\left(\mathrm{OC}_{2} \mathrm{H}_{5}\right)_{3}+3 \mathrm{H}_{2}$

$\mathrm{NaHSe}+\mathrm{H}_{2} \mathrm{SO}_{4} \longrightarrow \mathrm{H}_{2} \mathrm{Se}(\mathrm{g})+\mathrm{NaHSO}_{4}$

$2 \mathrm{HSCH}_{2} \mathrm{COOH}(\mathrm{TGA})+\mathrm{NaOH}+\mathrm{CdCl}_{2} \longrightarrow \mathrm{HSCH}_{2} \mathrm{COO}^{-} \mathrm{Cd}^{2+}$

$\mathrm{H}_{2} \mathrm{Se}(\mathrm{g})+\mathrm{HSCH}_{2} \mathrm{COO}^{-} \mathrm{Cd}^{2+} \longrightarrow \mathrm{CdSe}$ imaging, and bioconjugates due to their remarkable electronic and optic properties. First, TGA-capped CdSe QDs were easily and easily synthesized using reducing agents. The morphology and particle size of TGA-capped CdSe are shown in FIGURE II. Overall, the TGA-capped CdSe QDs were spherical particles with aggregation of small particle with 3 $5 \mathrm{~nm}$ size. FIGURE III. shows the UV-vis spectrum, photoluminescence (PL) spectrum, and DLS data of TGAcapped CdSe QDs. The absorbance spectrum displays an excitation peak at $428 \mathrm{~nm}$. The luminescence spectra at 610 $\mathrm{nm}$ are confirmed. In UV spectrum, the band gap and the size of the TGA-capped CdSe QDs was calculated as $2.24 \mathrm{eV}$ and $10.8 \mathrm{~nm}$, respectively. In DLS data, the size of the TGAcapped CdSe QDs was $84 \mathrm{~nm}$ because of aggregation of the small QDs with $6 \mathrm{~nm}$ each other. From these results, the TGA-capped CdSe QDs in aqueous solution was aggregated at room temperature. FIGURE IV. exhibits the mechanism of TGA-capped CdSe QDs onto electrode.

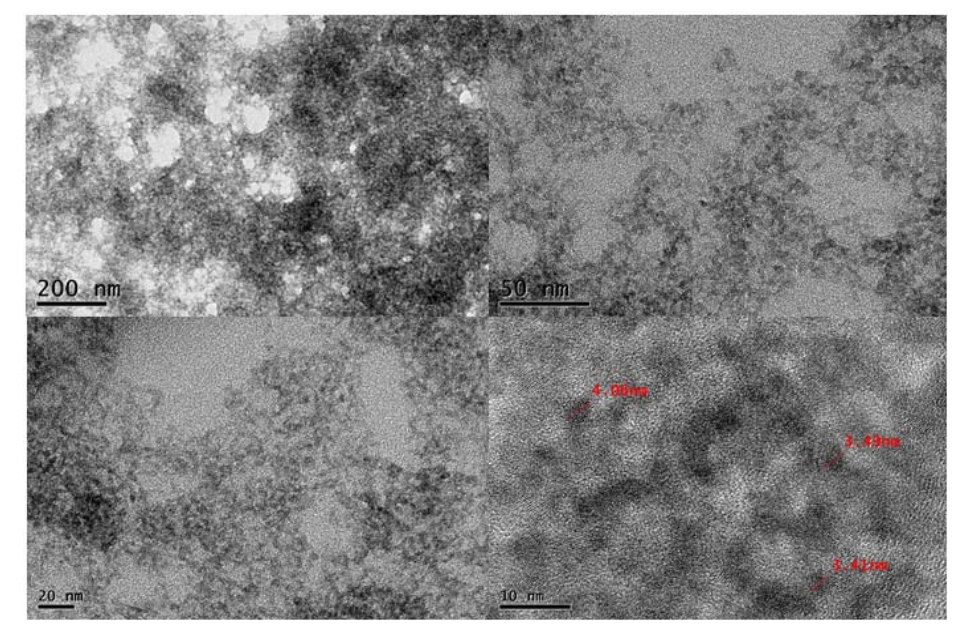

FIGURE II. TEM IMAGES OF THE TGA-CAPPED CdSe QDs 

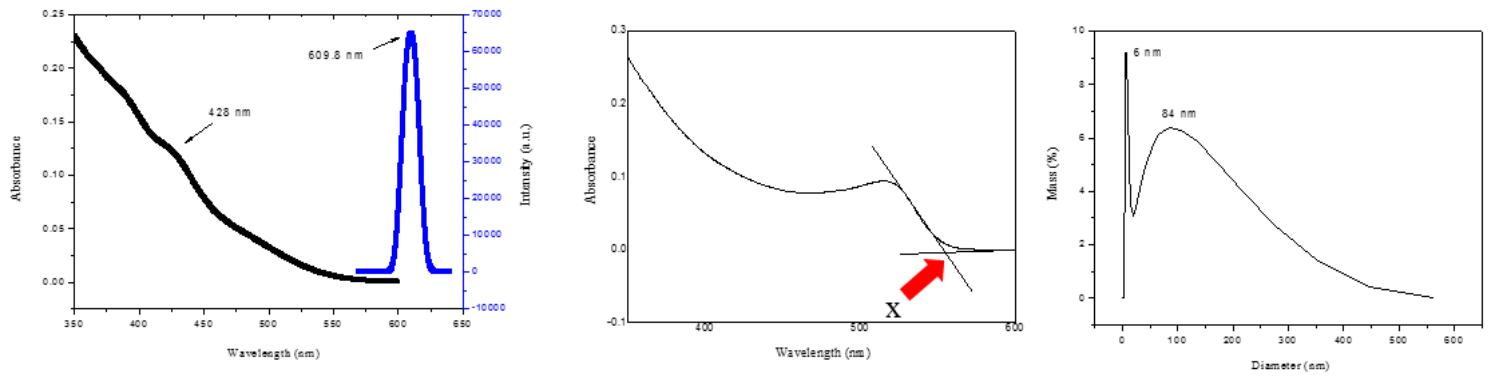

Band gap $(\mathrm{eV})=1240 / \mathrm{x}(2.24 \mathrm{eV})$
Size $(\mathrm{nm})=\left(-6.6521 \times 10^{-8}\right) \lambda_{\mathrm{uv}}{ }^{3}+\left(1.9557 \times 10^{-4}\right) \lambda_{\mathrm{uv}}{ }^{2}-\left(9.2352 \times 10^{-2}\right) \lambda_{\mathrm{uv}}+13.29(10.8 \mathrm{~nm})$

FIGURE III. UV-VISIBLE, PL SPECTRA, AND DLS DATA OF THE TGA-CAPPED CdSe QDs

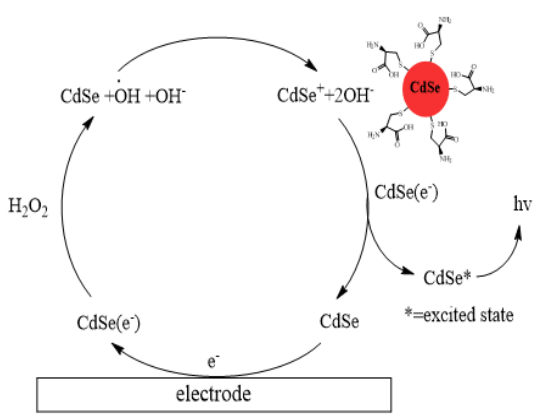

FIGURE IV. ECL MECHANISM OF TGA-CAPPED CdSe QDs

\section{CONCLUSION}

For preparation of a rapid and sensitive ECL biosensor based on CdSe QDs, the TGA-capped CdSe QDs was synthesized using chemical reduction, and their morphology and electrochemical properties were confirmed by TEM, DLS, UV-vis spectrum, and PL analysis. Also, the conjugated phenol compound was formed easily on the surface of the electrode by an electrochemical method, which was used for the immobilization of CdSe QDs and enzymes. In this luminescence mechanism, the ECL-potential signal of CdSe QDs resulted from the formation of $\mathrm{H}_{2} \mathrm{O}_{2}$ as a final decomposition component coming from a chemical reaction between glucose, glucose oxidase. Fabricated ECL biosensors based on CdSe QDs have great potential to provide rapid, sensitive, and cost-effective approaches for detection of glucose.

\section{REFERENCES}

[1] D. J. Jung, Journal of Nanoscience and Nanotechnology 10 (2010) 68556858.

[2] H.D. Kwen, Journal of Nanoscience and Nanotechnology 12 (2012) 6000-6004.

[3] Burda C, Chem. Rev. 105 (2005) 1025-1102.

[4] Li Z, Luminescence 26 (2011) 439-448.
[5] G. Jie, et al., Enhanced electrochemiluminescence of CdSe quantum dots composited with CNTs and PDDA for sensitive immunoassay, Biosensors and Bioelectronics, 2009. 24: p. 3352-3358.

[6] L. Yang, et al., Electrochemiluminescence Aptamer Biosensor for Detection of Thrombin Based on CdSe QDs/ACNTs Electrode, Electroanalysis, 2011. 23(4): p. 1007-1012.

[7] Pan, et al., Effects of Carbon Nanotubes on Photoluminescence Properties of Quantum Dots, Journal of Physical Chemistry C, 2008. 112(4): p. 939-944. 